\title{
Awareness of Pharmacists \& Pharmacy Students About Doping, and the Need for Doping Education in Iraq
}

\author{
Hasan Aldewachi ${ }^{1,2 *}$, Aya Raheem ${ }^{1}$, Wafaa Mohammed ${ }^{1}$ \\ ${ }^{1}$ College of Pharmacy, University of Mosul, Mosul, Iraq, 41001 \\ ${ }^{2}$ College of Pharmacy, Ninevah University, Mosul, Iraq, 41001 \\ "Corresponding author.Email:admin.affairs.pharm@uoninevah.edu.
}

\begin{abstract}
Objective. To evaluate the knowledge and views of pharmacists and pharmacists in sports and to investigate curriculum needs for sports pharmacy undergraduates

Methods. A web-based cross-sectional survey of pharmacy students was carried out from 2nd of Feb to 5th of March 2021 at the University of Mosul, College of Pharmacy. Survey Heart program have been used to collect data and process results.

Results. The online poll was completed by 276 individuals (40 percent response rate). Students have a knowledge score of about 50 percent on the banned status of substances that athletes can take. Students in pharmacy at the fourth year had considerably greater levels of knowledge than the other groups. The participants acknowledged the crucial role of pharmacists, especially health care practitioners, as consultants in sporting medication safety and effectiveness. More than $80 \%$ of participants supported the addition of sports pharmacy to the curriculum.

Conclusion. Pharmacy students expressed a great willingness to take part in doping prevention, and to guarantee that the medicines used by athletes are safe and reasonable. They proposed that a plan for sports pharmacy teaching and training in undergraduate drug courses be needed.
\end{abstract}

Keywords: doping knowledge, sports pharmacy, curriculum.

\section{INTRODUCTION}

Doping is the use of prohibited athletic medications by athletic competitors in competitive sports. The word doping is commonly used by sports competition regulators. The use of pharmaceuticals to improve performance by most international sports organizations, including the International Olympic Committee, is immoral and is thus forbidden [1]. In addition, the ethical breach of athletes (or sporting programs) is deeply disappointed in taking deliberate steps to escape discovery. Doping in sports has its beginnings in the very inception of sport alone. From the ancient use of chemicals in carriages to current basketball disputes, Over the years, common beliefs among athletes have widespread variety amongst countries. In recent decades, the overall tendency between authorities and sports bodies has been to control drugs in sport severely.

The prohibition is not limited to ensuring athletes' fairness but extends to the health concerns associated with substances that increase their performance and to the representational effect of drug-free sport on the public. Counter-doping authorities declare that use of pharmaceuticals to improve performance is contrary to the 'sporting spirit.' "If a person exercises sports for an improved quality of life, medications to improve performance may be harmful later, if a person is hooked to competition. Worldwide, sports have considerable economical and political relevance and are now an important part of society [2]. 
Pharmaceutical workers might be the first contact line for sportsmen and women requiring medicine or general health care guidance. However, few pharmacy programs, as shown by studies, include pharmacy sports as part of the curriculum. In undergraduate pharmacy programs, it was proposed that an education and training approach be required for sports pharmacy. Athletes have significant pressure to win and win in sports, from public to commercial. That leads to their performance improvement. Some use illicit substances to improve performance and/or prohibited methods such as blood transfusions $[3,4]$.

The use of medicines, food products and other efficient substances is a common and problematic phenomenon [5] In the case of a lack of understanding of doping and rules, athletes may accidentally consume drugs banned through self-medication and medical prescription, as Exemplified by a team doctor prescribing a common cold medicine containing a forbidden substance to an athlete during Sydney 2000 Olympic Games, Australia [6]. In Iraq, several OTC drugs that contain illegal chemicals are widely accessible. While it's extremely hard for all athletes to recognize and comprehend the WADA laws; thus, more informed experts like pharmacists are required to give aid and advice.

Drugs that enhance performance and enhance the image in society and especially in sports are frequently utilized. The National Institutes for Drug Abuse (NIDA) believes, for example, that over half a million kids of 8th and 10th grades have been using anabolism and that more high school senior citizens feel that steroids are not hazardous [7,8]. More than 1 million Americans, or $0,5 \%$ of the adult population, reported using anabolic steroids and two and a half million American athletes had used ephedrine [9] to stimulate their behavior. In addition, up to 5 percent of high school kids in the US have taken growth hormones to improve their athletic performance [10]. In 2013, 5271 adverse results (positive test results for banned drugs) were recorded worldwide in the World Anti-Doping Agency (WADA). Of those, anabolic agents accounted for 3320 (63\%), banned stimulants were 530 (10 percent), and Diuretics and other masking agents for $393(7.5 \%)$ [11].

Athletes are not just famous players, but also young people and amateur athletes. Similarly, this set of athletes must comprehend the effects of doping on their health and avoid inadvertent doping. Furthermore, they have to be able to interact regularly with a health care practitioner like a pharmacist at community-based pharmacies to help choose drugs and to buy them there. As all pharmacists can thus be advised in general pharmacy in the Community, an education program is necessary to teach pharmacy students in order to learn the danger of doping and the use of supplements. [1215].

Pharmacists can play an important part in anti-doping operations. These responsibilities might include teaching, counseling, administering, and monitoring medicines and supplements. Pharmacists can help by managing athletes' genuine medical needs, preventing them from inadvertently utilizing a prohibited drug. Pharmacists can also educate athletes and the general public about the health risks of taking performanceenhancing drugs (PEDs).

As a result, the current study sought to evaluate the existing knowledge and awareness of proper drug consumption, including doping and supplement use, among pharmacy students and pharmacists in Iraq, as well as the need for education.

\section{SURVEY METHODS}

A cross-sectional descriptive, web-based survey was performeded just among pharmacy professionals and students at many of Iraq Universities College of pharmacy as well as many Hospital pharmacists. The link to Survey Heart online web-based was sent via email to pharmacists in the 5 big cities (Baghdad, Mosul, Erbil, Tikrit and Sulaymaniyah). To increase the respondents and the credibility of the information in the survey, the answer was optional, not compulsory and unconditional, in order to not affect the validity of public information.

\subsection{Study Design}

This study took the form of a survey to examine the recognition, knowledge, and motivation of pharmacists and pharmacy students. The first section dealt with the general identification of doping; the second with information on previous cases of doping; the third with prohibited substances in OTC drugs and dietary supplements; the fourth concerned the relationship between athletes and the medical profession regarding anti-doping activities; the fifth concerning motivation to lecture on doping and the fourth deals with doping issues. A sample of 276 people from pharmacy students and pharmacists participated willingly. Participants were not asked for their identifying information, and students expressed their approval for participating in this study without their signature.

\subsection{Survey Questions}

Q1. Gender

Q2. Pharmacy professional year

Q3. Do you know what is doping agent is? 
Q4. Have you ever used doping agents or know someone consuming some like substances?

Q5. Have you ever heard about someone like a case with doping agent side effects?

Q6. Did you know that OTC medicines might contain prohibited substances?

Q7. Did you know that dietary supplements might contain prohibited substances?

Q8. In your opinion, why do athletes use doping substances

Q9. Who do you think should principally get involved in anti-doping activities for athletes?

Q10.Who do you think should be principally as an advisor about OTC dietary supplements that might contain Prohibited substances?

Q11.Did you know the names of Prohibited substances that might not show up on the ingredients label on dietary supplements?

Q12.The sources of your information about doping are from

Q13.Do you wish to take part in a lecture about doping in the foreseen future?

\section{SURVEY RESULTS}

276 students completed the online survey (response rate of $40 \%$, About $70 \%$ of all participants were female and $30 \%$ were male). The ratio was :(6.3\%) Academic degree, $(15.50 \%)$ hospital pharmacists and the majority $(41.7 \%)$ were 5 th stage students with $(7.7 \%)$ of 4 th stage students and $(28.8 \%)$ are other stages. Firstly asked about their knowledge about doping as showing in figure $1(26 \%)$ answered; illegal substance, while another quarter $(25.66 \%)$ said it's No need, drugs that can be harmful also less than $5 \%$ considered it as a cheating method, as well as, around $(16 \%)$ of the participants didn't have any information about it, while (28\%) stated that doping is harmful, illegal and a cheating method as well.

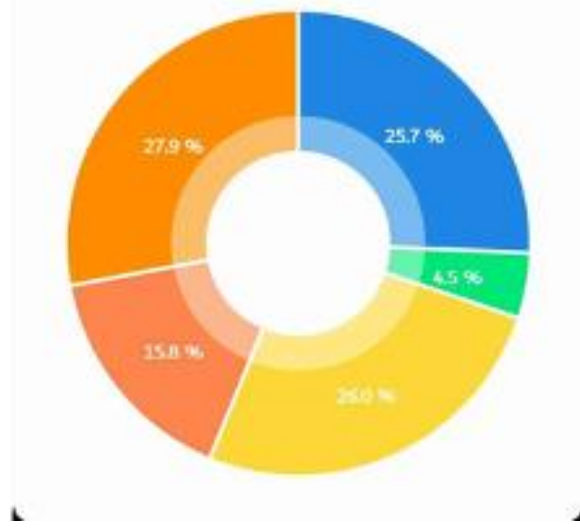

Figure 1 General knowledge of participants about doping

According to the questionnaire $(20.45 \%)$ of the participants had used doping agents or know someone consuming some like substances, however (79.56\%) said they didn't, while $(44.6 \%)$ had heard about someone like case with doping agent side effect but $(55.4 \%)$ didn't. On other hand, $(54.9 \%)$ of the participants believed that OTC medicines might contain prohibited substances but the other $(45.1 \%)$ don't. After that respondents were asked if dietary supplements might contain prohibited substances or not, (49.3\%) said yes and $(50.7 \%)$ said No.

Within the context of reasons that push athletes or young people to use doping agents, participants were asked about the reasons that might lead the use of doping substances and the opinions were like this : $(14.6 \%)$ to enhance their performance , $(6.4 \%)$ increase their endurance , $(16.1 \%)$ increase their muscle mass and strength, and the majority of the participants $(62.9 \%)$ infer it could be used for all those reasons.

In response to the question on who should mainly get involved in anti-doping activities for athletes respondents were allocated in an approximately equal proportion between doctors, or pharmacists (44\%) for each group while a very small proportion (1.9\%) thought nurses should be involved, while the remainder (10.2\%) said other members should be involved. But when they were asked who should be mainly as an advisor about OTC dietary supplements that might contain prohibited substances in figure 2 . The majority $(82.4 \%)$ answered the pharmacist should be, as they are the first line in the contact with the drugs and it's user, while $(13.5 \%)$ thought about the Doctors too, but only a few said $(1.1 \%)$ Nurse and $(3.0 \%)$ other medical staff. 
Who do you think should be mainly as an advisor about OTC dietary supplements that might contain prohibited substances

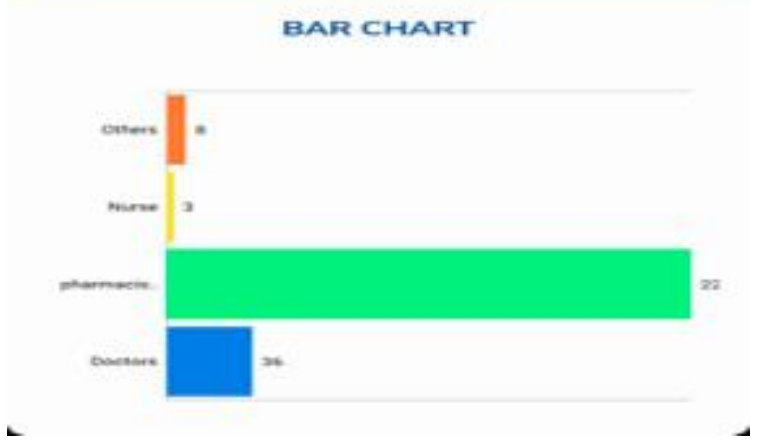

Figure 2 What participants think about who should be in charge as an advisor for OTC medicines

As well as we asked about their knowledge on dietary supplements that contain prohibited substances, but the names of prohibited substances might not appear on the ingredients label of dietary supplements, more than one half didn't know that $(51.7 \%)$ and $(48.3 \%)$ of the participants knew that (Table 1). Although the importance of doping subject, when we asked the participants about the sources of their information on doping the ratio was ; (18.4\%) from Doctors and health staff, $(37 \%)$ which was the majority said from social media ,(20.6\%)from books and magazines , with $(9.8 \%)$ from family and friends and (14.2\%) said their information is from other sources.

Table 1 Percentage of participants knowing about some doping facts.

\begin{tabular}{|c|c|c|}
\hline Questionnaire & $\begin{array}{c}\text { \% of } \\
\text { Yes }\end{array}$ & $\begin{array}{c}\text { \% of } \\
\text { No }\end{array}$ \\
\hline $\begin{array}{c}\text { Q4 Have you ever used doping or } \\
\text { know someone consuming some like } \\
\text { substances }\end{array}$ & 20.5 & 79.5 \\
\hline $\begin{array}{c}\text { Q5. Have you ever heard about } \\
\text { someone like case with doping agent } \\
\text { side effect }\end{array}$ & 44.6 & 54.4 \\
\hline $\begin{array}{c}\text { Q6. Did you know that the OTC } \\
\text { medicines might contain prohibited } \\
\text { substances? }\end{array}$ & 55 & 45 \\
\hline
\end{tabular}

Q7. Did you know that dietary supplements might contain prohibited substances?

Finally, most of the participants studied (81.58\%) had expressed their desire to attend a lecture about doping in the future and only $(18.42 \%)$ of them didn't want as shown in figure 3 .

Doctors and health staff - 49

Social media - 99

Books and magazines - 55

Family and friends - 26

other - 38

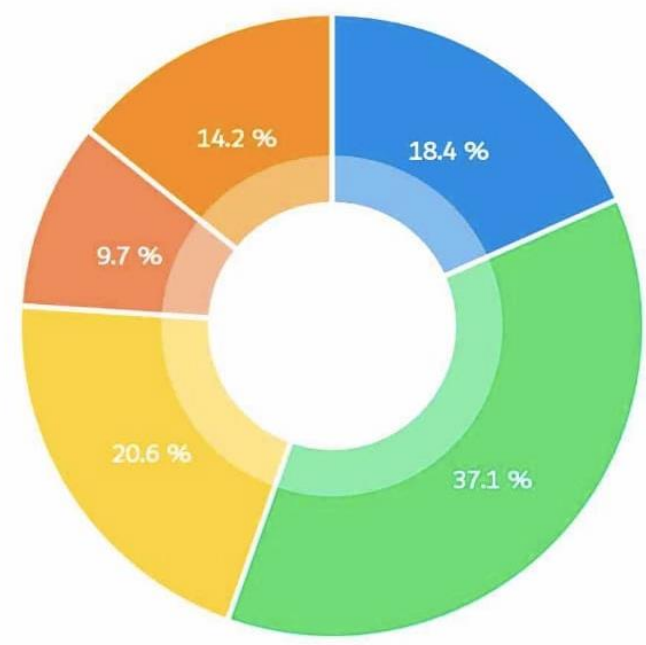

Figure 3 Participants being asked of their source of information about doping agents

\section{DISCUSSION}

Figures and tables should be placed either at the top or bottom of the page and close to the text referring to them if possiThere are limited formal educational options for pharmacists and pharmacy students. Educational programs in doping control and sports pharmacy must be created for college education, postgraduate training, and experiential activities. Classroom training should incorporate knowledge regarding PEDs as well as basic doping control concepts.

Education on PEDs and test technology is one of the student activities for an established advanced pharmacy practice experience, preparing and delivering presentations on these substances to athletes and others, 
doing literature research on medicines and dietary supplements used to boost athletic performance, creating a monograph on these substances, and taking part in doping monitoring programs. Many studies have been performed in various countries across the world on the role and understanding of pharmacy students or retail pharmacists in the field of doping and its health and legal consequences. [16-18].

\section{CONCLUSION}

Doping is one of the most serious problems for athletes, and it is essential that pharmacists have additional communication with athletes to guarantee safer drug handling. One of the most essential tasks of sports pharmacists, who are drug-use specialists for athletes, is education. Almost half of the pharmacists and pharmacy students who took part in this study were unaware that some over-the-counter (OTC) drugs may contain doping agents, and more than half were unaware that some nutritional supplements may contain doping agents; therefore, it is critical for pharmacy students to have more opportunities to learn about doping.

More sports pharmacist education and awareness would be beneficial for pharmacy students as well as athletes, and It would assist us in broadening the scope of what we can accomplish for sportsmen and society. ,As well as noticeable from the questionnaire, the participants had some basic knowledge and positive attitudes towards anti - doping in sports, while at the time of the study, sports pharmaceuticals were not included in the pharmacy program.

But knowledge gaps must bridged. Generally, the questioned students expressed interest and acknowledged the role that pharmacists might play in doping prevention. This study has significance for the development and implementation of sports pharmacy course modules or material. This will further reinforce WADA suggestions on the necessity of sports doping education programmes.

\section{AUTHORS' CONTRIBUTIONS}

H.A; contributed to proposal, advising, writing and organizing; A.R, contributed to data collection and writing; W.M contributed to data collection and writing.

\section{Conflict of Interest}

Authors would like to declare no conflict of interest.

\section{REFERENCES}

[1] Morente-Sánchez J, Zabala M. Doping in sport: A review of elite athletes' attitudes, beliefs and knowledge. Sports Med 2013;43(6):395-411. [http://dx.doi.org/10.1007/s40279-013-0037-x]

[2] FIP statement of professional standards: the role of the pharmacist in the fight against doping in sport. 2005.http://www.fip.org/www/ uploads/database_file.php?id=208\&table_id. Accessed August 3, 2014.

[3] Bloodworth AJ, Petróczi A, Bailey R, Pearce G, McNamee MJ. Doping and supplementation: the attitudes of talented young athletes.

[4] Bloodworth AJ, Petróczi A, Bailey R, Pearce G, McNamee MJ. Doping and supplementation: the attitudes of talented young athletes. Scand J Med Sci Sports. 2012;22(2):293-301 doi:10.1111/j.1600-0838.2010.01239.x.

[5] Ambrose PJ. Educational opportunities and antidoping roles and responsibilities for pharmacists. YakugakuZasshi. 2011;131(12):1761-1764.

[6] Ambrose PJ. Drug use in sports: a veritable arena for pharmacists. J Am Pharm Assoc. 2004;44(4):501514. quiz514-516. http://www.ncbi.nlm.nih.gov/pubmed/15372871. Accessed August 3, 2014.

[7] Tokish JM, Kocher MS, Hawkins RJ. Ergogenic aids: a review of basic science, performance, side effects, and status in sports. Am J Sports Med. 2004;32(6):1543-1553. DOI:10.1177/0363546504268041.

[8] Sjöqvist F, Garle M, Rane A. Use of doping agents, particularly anabolic steroids, in sports and society. Lancet. 2008;371(9627):1872-1882. doi:10.1016/S0140-6736(08)60801-6. [PubMed] [Google Scholar]

[9] Kanayama G, Gruber AJ, Pope HG, Borowiecki JJ, Hudson JI. Over-the-counter drug use in gymnasiums: an underrecognized substance abuse problem? PsychotherPsychosom. 2001;70(3):137140. doi:56238.

[10] Saugy M, Robinson N, Saudan C, Baume N, Avois L, Mangin P. Human growth hormone doping in sport. Br J Sports Med. 2006;40(Suppl 1):i35-39. DOI:10.1136/bjsm.2006.027573.

[11] World Anti-Doping Agency. 2013. Laboratory Report Anti-Doping Testing Figures.

[12] Ambrose PJ. An advanced pharmacy practice experience in sports pharmacy Am J Pharm Educ. 2008;72:19.

[13] Jenkinson DM, Harbert AJ. Supplements and sports. Am Fam Physician 2008;78(9):1039-1046.

[14] Geyer H, Braun H, Burke LM, Stear SJ, Castell LM. A-Z of dietary supplements: Dietary supplements, sports nutrition foods and ergogenic 
aids for health and performance - Part 22. Br J Sports Med 2011;45(9):752-754.

[15] Harel Z, Harel S, Wald R, Mamdani M, Bell CM. The frequency and characteristics of dietary supplement recalls in the United States. JAMA Intern Med 2013;173(10):926-928.

[16] Laure, P., and A. Kriebitzsch-Lejeune. "Retail pharmacists and doping in sports: Knowledge and attitudes. A national survey in France." Science \& sports 15.3 (2000): 141-146.

[17] Shibata, Keita, Koichi Ichikawa, and Naomi Kurata. "Knowledge of pharmacy students about doping, and the need for doping education: a questionnaire survey." BMC research notes 10.1 (2017): 1-10.

[18] Awaisu, Ahmed, David Mottram, AlaaRahhal, Bayan Alemrayat, Afif Ahmed, Mark Stuart, and Sherief Khalifa "Knowledge and perceptions of pharmacy students in Qatar on anti-doping in sports and on sports pharmacy in undergraduate curricula." American journal of pharmaceutical education 79.8 (2015). 